\title{
Lymphatic malformations in children: treatment outcomes of sclerotherapy in a large cohort
}

\author{
Frédérique C. M. Bouwman ${ }^{1,2,4}$ (D) Silje S. Kooijman ${ }^{1}$ • Bas H. Verhoeven ${ }^{1,4} \cdot$ Leo J. Schultze Kool ${ }^{2,4}$ • Carine J. M. van \\ der Vleuten ${ }^{3,4}$. Sanne M. B. I. Botden ${ }^{1,4} \cdot$ Ivo de Blaauw $^{1}$
}

Received: 24 June 2019 / Revised: 3 August 2020 / Accepted: 14 September 2020 / Published online: 13 October 2020

(C) The Author(s) 2020

\begin{abstract}
This retrospective study examines the outcomes of sclerotherapy in children with (veno)lymphatic malformations who received sclerotherapy between 2011 and 2016 (116 children, 234 procedures). Complication severity was classified using the Society of Interventional Radiology classification. Clinical response was rated on a scale of 0 (no change) to 3 (good improvement). The sclerosants used were bleomycin $(n=132 ; 56 \%)$, lauromacrogol $(n=42 ; 18 \%)$, doxycycline $(n=15 ; 6 \%)$, ethanol $(n=12 ; 5 \%)$, or a combination $(n=33 ; 14 \%)$. Four major and 25 minor complications occurred without significant differences between the agents. The median response rate per procedure was 2 - some improvement—for all sclerosants. However, in pure LMs (67\%), bleomycin and a combination of agents resulted in the best clinical response. On patient level, all had some or good clinical response. Mixed macrocystic and microcystic lesions showed a significantly lower clinical response (median 2 versus $3 ; p=$ 0.023 and $p=0.036$, respectively) and required significantly more procedures (median 2 versus $1 ; p=0.043$ and $p=0.044$, respectively) compared with lesions with one component.

Conclusion: Sclerotherapy for (V)LMs in children is safe and effective. Bleomycin is the most frequently used agent in this clinic and seemed most effective for pure LMs. Mixed macrocystic and microcystic lesions are most difficult to treat effectively.
\end{abstract}

What is Known:

- A variety of agents can be used for sclerotherapy of lymphatic malformations in children.

- Macrocystic lesions have favorable outcomes compared with microcystic and mixed lesions.

What is New:

- Bleomycin and a combination of agents seem to be most effective to treat lymphatic malformations in children.

- Mixed macrocystic and microcystic lesions are more difficult to treat effectively compared with lesions with either one of these components.

Communicated by Piet Leroy

Frédérique C. M. Bouwman

Frederique.Bouwman@radboudumc.nl

Silje S. Kooijman

Silje.Kooijman@radboudumc.nl

Bas H. Verhoeven

Bas.Verhoeven@radboudumc.nl

Leo J. Schultze Kool

Leo.SchultzeKool@ radboudumc.nl

Carine J. M. van der Vleuten

Carine.vanderVleuten@ radboudumc.nl

Sanne M. B. I. Botden

Sanne.Botden@radboudumc.nl
Ivo de Blaauw

Ivo.deBlaauw@radboudumc.nl

1 Department of Surgery, Division of Pediatric Surgery, Radboudumc-Amalia Children's Hospital, Nijmegen, Netherlands

2 Department of Radiology and Nuclear Medicine, Division of Interventional Radiology, Radboud University Medical Center (Radboudumc), Nijmegen, Netherlands

3 Department of Dermatology, Radboud University Medical Center (Radboudumc), Nijmegen, Netherlands

4 Center for Vascular Anomalies, Hecovan, Radboud University Medical Center (Radboudumc), VASCERN VASCA European Reference Center, Nijmegen, Netherlands 
Keywords Lymphatic malformation $\cdot$ Vascular malformation $\cdot$ Sclerotherapy $\cdot$ Bleomycin $\cdot$ Lauromacrogol

\author{
Abbreviations \\ LMs Lymphatic malformations \\ VLMs Venolymphatic malformations
}

\section{Introduction}

Lymphatic malformations (LMs) are congenital developmental anomalies of the lymphatic system, with or without a venous component (venolymphatic malformation; VLM) [1]. The incidence is estimated to be 1 in 2000-6000 live births [2-5]. Symptoms, often named lesion-related complications, vary from pain and swelling to relapsing periods of infection and distortion of anatomical structures. Sclerotherapy is currently the gold standard for (V)LM treatment if invasive management is indicated [6], and a wide range of sclerosing agents have been used in daily practice, including bleomycin, lauromacrogol, doxycycline, ethanol, and picibanil.

Several studies evaluated treatment outcomes after use of various agents for sclerotherapy in (V)LMs [7-17]. However, most of these studies included small patient cohorts $[9,16,17]$ or both adults and children $[8,11,12,15]$, which could confound or bias the results. Among these studies, those examining larger pediatric cohorts lack information on bleomycin $[10,13,14]$, which is currently one of the most frequently used agents worldwide. In a systematic review on agents used for sclerotherapy, it is concluded that the optimal sclerotherapy could not be identified and that the difference in complication rates could be the deciding factor in the choice between agents [18].

Therefore, this study evaluates sclerotherapy outcomes of (V)LMs in children treated in a high volume center where different sclerosing agents are being used. These data will provide more insight into the optimal agent for sclerotherapy of (V)LMs and will provide guidance in the counseling of children and their parents on the treatment and prognosis.

\section{Methods}

\section{Data collection}

A retrospective analysis was performed of all children $(<18$ years of age) with (V)LMs who received percutaneous sclerotherapy between January 2011 and December 2016. Minimal follow-up was 6 months. All patients were treated at the expertise center for hemangiomas and congenital vascular malformations (HECOVAN) at the Radboudumc-Amalia Children's Hospital in Nijmegen, Netherlands. The local ethical committee approved this study.

Medical records were reviewed for patient age at diagnosis and procedure, sex, comorbidity, the number of sclerotherapy procedures during the study period, and the lesion-related complications prior to sclerotherapy. Lesion characteristics included anatomical location and morphological subtype. As regards the anatomical location, six regions were defined: (1) head/neck area, (2) thorax, (3) abdomen/pelvis, (4) upper extremity, (5) lower extremity, and (6) abdomen/pelvis and lower extremity. Morphologically, the lesions were classified as macrocystic, microcystic, or mixed macro- and microcystic and, secondly, as pure lymphatic (LM) or venolymphatic (VLM). The difference between macrocystic and microcystic was defined by the size and accessibility of the cysts $[1,6,8$, 19]. Macrocystic lesions contain cysts $\geq 2 \mathrm{~cm}$ or considered accessible for aspiration based on ultrasound. Microcystic lesions contain cysts $<2 \mathrm{~cm}$ or considered inaccessible for aspiration. Mixed lesions contain both macrocystic and microcystic components. VLMs have both venous and lymphatic components.

\section{Outcome parameters}

The outcome parameters were short-term $(<30$ days $)$ and long-term procedure-related complications and clinical response rate. Post-treatment pain, local swelling, and transient fever without focus of infection were not considered complications, but expected side effects of sclerotherapy. The procedure-related complications were classified as minor or major according to the Society of Interventional Radiology (SIR) Classification System for Complications by Outcome (Table 1) [20]. Nominal therapy included oral antibiotic treatment. Complications requiring intravenous antibiotic treatment and thus hospitalization were classified as major.

Table 1 SIR

Classification system for complications by outcome [20] 
The clinical response was based on documentation in the patient records, similar to other studies [8, 10], and expressed on a scale of zero to three. Zero represents no response to treatment. One represents slight improvement, defined as little regression compared with the original size with almost no cosmetic relief or functional improvement. Two represents some improvement, defined as visible regression of the lesion compared with the original size with some cosmetic relief or functional improvement. Three represents a good response, defined as total or near-total volume reduction of the lesion with no or minimal residual cosmetic or functional impairment.

\section{Technique of sclerotherapy}

Sclerotherapy is performed under general anesthesia. Sclerotherapy of lymphatic malformations in children can be challenging due to the small size of the cysts or lymph vessels and the limited safety margins of the agents used. In addition, some of the agents could generate an intense pain response. General anesthesia generates a controlled environment, facilitating targeted sclerotherapy: limiting the number of injections and radiation hazard needed and injecting the sclerosing agent as specific as possible. In our opinion, sclerotherapy under general anesthesia also minimizes psychic trauma. This is an important part to take into account, in particular because a treatment course of sclerotherapy could include multiple sessions.

After puncturing the lesion with a 21-23 gauge needle using ultrasound guidance, as much fluid as possible is aspirated. Either bleomycin (Bleomedac, Lamepro BV, Breda, Netherlands; $600 \mathrm{IU} / \mathrm{kg}$, age < 1 year: $\max 10.000 \mathrm{IU}$, age > 1 year: max 15.000 IU per session), lauromacrogol (Aethoxysklerol, Chemical Factory Kreussler \& Co., Wiesbaden, Germany; either as a liquid with a concentration of $2 \%$ or as foam; $2 \mathrm{ml}$ lauromacrogol $2 \%$ with $8 \mathrm{ml}$ sterile room air, max 20-30 ml foam), doxycycline (Vibramycin, Pfizer, Capelle aan den IJssel, Netherlands; $10 \mathrm{mg} / \mathrm{ml}$, max $20 \mathrm{mg} / \mathrm{kg}$ ), or ethanol (Alcohol, Pharmacy A15, Gorinchem, Netherlands; $\max 0.14 \mathrm{ml} / \mathrm{kg} / 10$ minutes and $\max 0.5-1.0 \mathrm{ml} /$ $\mathrm{kg}$ per session) is injected under ultrasound guidance. Ethanol sclerotherapy for macrocystic lesions involves both injection and subsequent aspiration of the agent (rinsing). Additional fluoroscopy guidance is used in case of macrocystic lesions or a (suspected) venous component to visualize drainage into normal soft tissue or circulation.

\section{Choice of used agent}

Bleomycin is the preferred sclerosant for LMs in our center and also one of the most frequently used agents worldwide [18]. The choice for another agent or a combination of agents was based on location, content, extent, morphological type of the (V)LM, and volume of bleomycin that could be used based on weight of the patient and the cumulative lifetime dose. At locations where only minimal swelling was allowed, such as the eyelid or in close proximity to a nerve, bleomycin was highly preferred over one of the other agents. In other cases, when swelling was allowed, for example, in case of an intra-abdominally located lesion, ethanol or lauromacrogol was used. Another aspect was the morphological subtype of the lesion. Microcystic lesions were preferably treated with bleomycin or doxycycline. The agent of choice for macrocystic lesions depended on the location as described previously. Venolymphatic malformations were often treated with ethanol or lauromacrogol in addition to bleomycin, because of the venous component. Ethanol was used preferentially in more severe or extensive lesions, and a combination of agents was often used in case of large lesions.

\section{Statistical analyses}

Complications and response rates were compared on patient and procedure level between the different sclerosing agents, the regions of anatomical location, and the morphological subtypes. The statistical analyses were performed with IBM SPSS statistical software version 25. Categorical data were presented as frequencies and percentages and analyzed using Pearson's chi-square or Fisher's exact test where appropriate. For continuous data, means and standard deviations or medians and ranges were calculated depending on the distribution of data. For the results of clinical response (ordinal data), both means and medians were calculated. Analyses were performed using the independent $t$ test or the ANOVA in case of normal distribution and the Mann-Whitney $U$ test or Kruskal-Wallis test in case of non-normal distribution. A $p$ value of $<0.05$ was considered significant.

\section{Results}

\section{Patient demographics and lesion characteristics}

A total of 234 sclerotherapy procedures were performed in 116 children (53 males, 63 females) during the study period. Table 2 summarizes the lesion characteristics of this study population. A pure LM was diagnosed in 78 patients $(67 \%)$ and a VLM in 38 patients $(33 \%)$. Age at first sclerotherapy procedure ranged from 1 day to 9 years, with a median of 7 years. Four patients required ex-utero intrapartum therapy (EXIT) with direct endotracheal intubation because of a potentially airwaythreatening LM. Five patients had a (V)LM in the context of lymphangiomatosis $(n=2)$ or Klippel-Trenaunay syndrome $(n=2)$. 
Table 2 Lesion characteristics

Total group $(n=116)$

\begin{tabular}{ll} 
Diagnosis of the lesion & \\
In utero & $15(13 \%)$ \\
At birth & $47(41 \%)$ \\
$<1$ year & $12(10 \%)$ \\
1-2 years & $10(9 \%)$ \\
$>2$ years & $30(26 \%)$ \\
Type of malformation & \\
Pure lymphatic & $78(67 \%)$ \\
Venolymphatic & $38(33 \%)$ \\
Morphological subtype & \\
Macrocystic & $57(49 \%)$ \\
Microcystic & $22(19 \%)$ \\
Mixed & $37(32 \%)$ \\
Anatomical location & \\
Head and neck & $57(49 \%)$ \\
Thorax & $20(17 \%)$ \\
Abdomen and pelvis & $14(12 \%)$ \\
Upper extremity & $8(7 \%)$ \\
Lower extremity & $10(9 \%)$ \\
Abdomen/pelvis/lower extremity & $7(6 \%)$ \\
Lesion-related complications & \\
Increase in size & $70(60 \%)$ \\
Pain & $50(43 \%)$ \\
Functional impairment & $37(32 \%)$ \\
Cosmetically disturbing lesion & $34(29 \%)$ \\
Infection & $13(11 \%)$ \\
Bleeding & $11(9 \%)$ \\
Airway permeability threatened & $10(9 \%)$ \\
\hline & $6(5 \%)$ \\
\hline
\end{tabular}

Most patients suffered from multiple lesion-related complications before the first procedure during the study period (Table 2). Sixteen patients (14\%) required treatment for their lesion-related complications prior to the study period, including antibiotics $(n=7)$, tracheal cannulation $(n=2)$, cyst drainage because of compression $(n=2)$, and amputation of the lower leg $(n=1)$. One-third of the patients $(n=36)$ received treatment for their malformations prior to the study period, of whom nine $(8 \%)$ had a surgical resection.

The median number of sclerotherapy procedures per patient during the study period was one (range 1-13). Of all patients, $55 \%$ received one and $18 \%$ two procedures. The sclerosing agents used were bleomycin $(n=132 ; 56 \%)$, lauromacrogol $(n=42 ; 18 \%)$, doxycycline $(n=15 ; 6 \%)$, ethanol $(n=12 ; 5 \%)$, or a combination of agents $(n=33 ; 14 \%)$. Combination therapy consisted of bleomycin and ethanol $(n=$ $6)$, bleomycin and lauromacrogol $(n=19)$, or lauromacrogol and ethanol $(n=8)$.

\section{Procedure-related complications}

A total of 25 minor and four major complications were identified in 24 patients. No known cases of pulmonary toxicity were seen during the study period. Table 3 shows the procedure-related complications in the total group and for each sclerosing agent used. No significant differences were found in the occurrence of complications between the agents and between the different morphological subtypes. Postprocedural pain was an expected outcome, although it was specifically reported in twelve patients, of which seven treated with bleomycin, two with doxycycline, and the remainder all with different combinations of sclerosants.

A total of 22 short-term minor complications were identified. Hematoma was the most common complication $(n=16)$. Two patients were treated with oral antibiotics for an infection. One of these patients had a tracheal cannula because of the LM and developed pneumonia 7 days after sclerotherapy with bleomycin. The four "other" complications were skin necrosis $(n=1$; bleomycin), febrile convulsion ( $n=1$; bleomycin), blistering ( $n$ $=1$; lauromacrogol), and stridor ( $n=1$; lauromacrogol).

Four patients developed a short-term major complication. Two patients were diagnosed with an abscessed LM cyst, for which antibiotic treatment and drainage of the cyst were indicated. Two patients suffered from severe post-procedural swelling with functional impairment. One of these developed an abnormal gait and the other a reduced vision to $15 \%$. Both required a resection of the swollen LM to reduce the functional impairment.

Three long-term procedure-related complications occurred during the study period, all after treatment with bleomycin. These were scarring, hyperpigmentation, and lymphedema. The lymphedema was treated with compression therapy.

\section{Clinical response rate}

The clinical response to sclerotherapy with the various agents per procedure is summarized in Table 4. A total of 214 procedures $(91 \%)$ resulted in "some" $(n=160 ; 68 \%)$ or "good" $(n$ $=54 ; 23 \%$ ) clinical improvement. A response of 2 (some) or 3 (good) was reported after $93 \%$ of the procedures in case of bleomycin or lauromacrogol injection, $75 \%$ after ethanol, $73 \%$ after doxycycline, and $97 \%$ after injection of a combination of agents. Table 5 shows the post hoc analysis of the differences in response rates shown in Table 4. For the total group, bleomycin and a combination of agents were significantly better than doxycycline (means 2.2 and 2.1 versus 1.7 , $p=0.010$ and $p=0.030$ ). In pure lymphatic lesions, bleomycin (mean 2.2) and a combination of agents (mean 2.3) were significantly better than both doxycycline (mean 1.7; $p=0.021$ and $p=0.014$ ) and ethanol (mean 1.4; $p=$ 0.023 and $p=0.020$ ). Lauromacrogol resulted in a mean response rate of 2.1 ; this was not significantly different compared with the other agents. 
Table 3 Procedure-related complications

\begin{tabular}{|c|c|c|c|c|c|c|c|}
\hline & $\begin{array}{l}\text { Total Group } \\
(n=234)\end{array}$ & $\begin{array}{l}\text { Bleomycin } \\
(n=132)\end{array}$ & $\begin{array}{l}\text { Lauromacrogol } \\
(n=42)\end{array}$ & $\begin{array}{l}\text { Doxycycline } \\
(n=15)\end{array}$ & $\begin{array}{l}\text { Ethanol } \\
(n=12)\end{array}$ & $\begin{array}{l}\text { Combination } \\
(n=33)\end{array}$ & $p$ value \\
\hline Short term & $26(11 \%)$ & $15(11 \%)$ & $5(12 \%)$ & $2(13 \%)$ & - & $4(12 \%)$ & 0.792 \\
\hline \multicolumn{8}{|l|}{ Minor } \\
\hline Hematoma & 16 & 10 & 2 & 1 & - & 3 & 0.819 \\
\hline Other & 4 & 2 & 2 & - & - & - & 0.493 \\
\hline Infection & 2 & 1 & - & - & - & 1 & 0.653 \\
\hline \multicolumn{8}{|l|}{ Major } \\
\hline Infection/abscess & 2 & 1 & - & 1 & - & - & 0.150 \\
\hline $\begin{array}{l}\text { Functional } \\
\text { impairment }\end{array}$ & 2 & 1 & 1 & - & - & - & 0.793 \\
\hline Long term & $3(1 \%)$ & $3(2 \%)$ & - & - & - & - & 0.672 \\
\hline \multicolumn{8}{|l|}{ Minor } \\
\hline Scarring & 1 & 1 & - & - & - & - & 0.942 \\
\hline Hyperpigmentation & 1 & 1 & - & - & - & - & 0.942 \\
\hline Lymphoedema & 1 & 1 & - & - & - & - & 0.942 \\
\hline
\end{tabular}

In the evaluation on patient level, at the end of the study period, 65 patients $(56 \%)$ had shown some clinical response after a median of two procedures (range 1-13), and 51 patients (44\%) had shown good clinical response after a median of one procedure (range 1-4). The clinical response per patient was significantly influenced by the morphological subtype of the lesion $(p=$ $0.042)$ and the location of the lesion $(p=0.043)$. The clinical response was better in macrocystic (median 3, range 2-3) and microcystic lesions (median 3, range 2-3) compared with mixed lesions (median 2, range 2-3; $p=0.023$ and $p=0.036$, respectively). The number of procedures performed per patient during the study period was also significantly higher in patients with a mixed lesion (median 2, range 1-13) compared with patients with a macrocystic (median 1 , range $1-7 ; p=0.043$ ) or microcystic lesion (median 1 , range $1-5 ; p=0.044$ ). The median response in patients with a lesion in the head and neck area was significantly better (median 3 ) than in patients with a lesion in the abdomen and pelvis (median $2 ; p=0.028$ ) or in the upper extremity (me$\operatorname{dian} 2 ; p=0.028$ ). At the end of the study period, seven patients of this cohort received treatment with an mTOR inhibitor due to an insufficient response to sclerotherapy on the long term.

\section{Discussion}

This study aimed to evaluate the treatment of (V)LMs in a large pediatric cohort and found that bleomycin and a combination of agents were superior in the treatment of pure LMs. Furthermore, the study indicates that lesions with both macrocystic and microcystic components are more difficult to treat than lesions with either one of these components.

This study shows that all sclerosing agents are effective with some or good clinical improvement after $91 \%$ of the procedures. On patient level, all patients had shown some or good clinical response at the end of the study period. This is a good outcome compared with the range described in the systematic review of Horbach et al. showing an overall response rate ranging from 67 to $100 \%$ per patient [18].

The present study indicates that bleomycin and a combination of agents result in a better clinical response compared with doxycycline and ethanol. However, caution must be applied with the interpretation of our data, because doxycycline and especially ethanol were used in specific cases in this cohort. Doxycycline was used, for example, when bleomycin was

Table 4 Response rate per procedure

\begin{tabular}{llllllll}
\hline Response rate (scale 0-3) & Total Group & Bleomycin & Lauromacrogol & Doxycycline & Ethanol & Combination & $p$ value \\
\hline Total group & $n=234$ & $n=132$ & $n=42$ & $n=15$ & $n=12$ & $n=33$ \\
Mean & 2.1 & 2.2 & 2.1 & 1.7 & 1.9 & 2.1 \\
Median (range) & $2(0-3)$ & $2(0-3)$ & $2(0-3)$ & $2(0-3)$ & $2(0-3)$ & $2(0-3)$ \\
Pure lymphatic & $n=142$ & $n=98$ & $n=14$ & $n=10$ & $n=5$ & $n=15$ \\
Mean & 2.1 & 2.2 & 2.0 & $2(0-3)$ & $2(0-2)$ & $2(0-2)$ & $2(2-3)$ \\
Median (range) & $2(0-3)$ & $2(0-3)$ & $n=28$ & $n=5$ & $n=7$ & $n=18$ \\
Venolymphatic & $n=92$ & $n=34$ & 2.1 & 1.8 & 2.3 & 1.9 \\
Mean & 2.1 & 2.1 & $2(0-3)$ & $2(1-3)$ & $2(1-3)$ & $2(1-3)$ & $2(0-3)$ \\
median (range) & $2(0-3)$ & $2(0)$ & 0.41 \\
\hline
\end{tabular}


Table 5 Post hoc analysis of response rate per procedure

\begin{tabular}{lll}
\hline & Total group & Pure lymphatic \\
\hline$p$ value & 0.071 & 0.021 \\
Bleomycin vs doxycycline & 0.010 & 0.021 \\
Bleomycin vs ethanol & 0.282 & 0.023 \\
Combination vs doxycycline & 0.030 & 0.014 \\
Combination vs ethanol & 0.488 & 0.020 \\
Lauromacrogol vs doxycycline & 0.061 & 0.641 \\
Lauromacrogol vs ethanol & 0.243 & 0.147 \\
\hline
\end{tabular}

relatively contraindicated or not available. Ethanol is the preferred agent, based on expert opinion, for more severe or extensive lesions or lesions with a venous component. Unfortunately, these data only included a small number of patients.

On patient level, the response rates were significantly influenced by the morphological subtype: (V)LMs with both macrocystic and microcystic components were found to have lower response rates than lesions with either one of these components. The median number of procedures per patient was also higher in these mixed (V)LMs. It has been described previously that better results were achieved in macrocystic LMs compared with microcystic and/or mixed lesions [7, 9, 21-25]. However, in contrast to these studies, the present study shows that the results in microcystic lesions were similar to those in macrocystic lesions. Despite the good results for microcystic and macrocystic lesions, it is unexplained why mixed lesions responded inferiorly to sclerotherapy.

This study shows that sclerotherapy is a good first-line treatment for (V)LMs in case invasive management is necessary. However, the beneficial results of sclerotherapy do not always persist on the long term or patients suffer from residual disease [26], which was also the case in some patients in this cohort. The mTOR inhibitor sirolimus has been found to be effective in lymphatic malformations that were refractory to standard treatment $[27,28]$. Current clinical trials further investigate the use of sirolimus and which patients would benefit most from this treatment, with or without sclerotherapy or surgery.

Regarding the complication rates, no significant differences were found between the sclerosing agents nor the different morphological subtypes. Bleomycin is currently one of the most frequently used sclerosing agents worldwide, and complications rates in literature range from 0 to $20 \%[6,12$, 19, 29-34]. The most common complications reported are infections, hematomas, and hyperpigmentation [6, 31, 32, $34,35]$, which is in accordance with our results (Table 3).

A major concern in the use of bleomycin is the risk of pulmonary toxicity, which is shown to be a rare and doserelated risk [36]. In this study, being one of the largest cohorts studied, no known cases of pulmonary toxicity were identified. Thus, the risk of bleomycin-induced pulmonary toxicity seems to be negligible when used in dosages documented in our protocol. The patient who developed a pneumonia after bleomycin injection had a bacterial pneumonia and furthermore a high risk a priori because of a tracheal cannula in situ. Currently, no standard follow-up protocol is used in our hospital to quantify pulmonary function after use of bleomycin. Whether the addition of pulmonary function tests and/or radiographic assessment to current standard care is useful and cost-effective in the detection of pulmonary complications after use of bleomycin has not yet been clarified.

Regarding the other agents used in our center, complication rates were similar to those reported in other studies $[5,21,22$, $37-42]$. The complication rate of lauromacrogol ranged from 0 to $24 \%$ in literature, including infections (3\%) and hematomas $(13-24 \%)$ [21, 37]. Our population had a complication rate of $12 \%$ without infections and fewer cases of hematomas $(5 \%)$. Complication rates after doxycycline injection ranged from 0 to $14 \%$ in literature, including infection and hemorrhage $[5,22,38-40]$, which was similar in our study population (13\%). Ethanol was only used in a few exceptional cases, and no complications were identified, which is in accordance to known studies [41, 42].

This study has some limitations inherent to the retrospective study design, in which randomization of the agent was not performed. Considerations on which agent to be used in specific cases were based on expert opinion, since no international guidelines are currently available. Unfortunately, the reason of this choice was not always well documented. The size of the study is a strength in comparison with other studies, but still the reliability of statistical analyses is limited for smaller subgroups. The response rate was determined based on clinical descriptions in the patients' records, which is subject to the perception of the physician. This may influence the reliability of data, but it probably does not compromise the ability to assess for trends. Future studies are recommended to investigate which approach is best to measure and quantify response after sclerotherapy of (V)LMs, for example, patient-reported outcomes, physical examination, or post-procedural imaging. In these studies, it could be beneficial to use the updated SIR classification, if this is validated properly for a widespread use [43]. Patient-related outcomes are particularly important to focus on in future studies, as proposed by the OVAMA project [44]. In this consensus study, a core outcome set was developed for clinical research on peripheral vascular malformations, and international consensus was reached that patient-reported outcomes play a significant role. These include the item pain and it would be interesting to investigate the differences in intensity and duration of pain between various sclerosing agents. Overall, prospective studies are needed to strengthen the results to determine the most potent sclerosing agent in each subtype and to develop guidelines for patient- or lesion-specific care. 


\section{Conclusions}

Complication rates after sclerotherapy of (veno)lymphatic malformations in children are low and mostly include minor complications. No significant differences were found in complication rates between the different sclerosing agents. All agents are effective; however, bleomycin and a combination of agents seem to be most effective in the treatment of pure lymphatic malformations. In clinical care, special attention should be paid to mixed macrocystic and microcystic (veno)lymphatic malformations, because the results of this study indicate that these lesions are more difficult to treat effectively compared with lesions with either one of these components.

Authors' contributions F.C.M. Bouwman: conceptualization/design, methodology, investigation, data collection, analysis, and writing the manuscript (initial manuscript and editing).

S.S. Kooijman: methodology, investigation, data collection, analysis, and drafting the initial manuscript.

B.H. Verhoeven: conceptualization/design, methodology, supervision, and writing (review the manuscript).

L.J. Schultze Kool: conceptualization/design, methodology, and writing (review the manuscript).

C.J.M. van der Vleuten: methodology and writing (review the manuscript).

S.M.B.I. Botden: conceptualization/design, methodology, investigation, supervision, and writing (review/editing the manuscript).

I. de Blaauw: conceptualization/design, methodology, supervision, and writing (review the manuscript).

\section{Compliance with ethical standards}

Conflict of interest The authors declare that they have no conflict of interest.

Ethical approval All procedures performed were in accordance with the ethical standards of the institutional research committee (Radboudumc Committee on Research Involving Human Subjects, reference number 2017-3850) and with the 1964 Helsinki declaration and its later amendments or comparable ethical standards.

Informed consent The local ethical committee approved the review of medical and imaging records for this study and waived informed consent.

Open Access This article is licensed under a Creative Commons Attribution 4.0 International License, which permits use, sharing, adaptation, distribution and reproduction in any medium or format, as long as you give appropriate credit to the original author(s) and the source, provide a link to the Creative Commons licence, and indicate if changes were made. The images or other third party material in this article are included in the article's Creative Commons licence, unless indicated otherwise in a credit line to the material. If material is not included in the article's Creative Commons licence and your intended use is not permitted by statutory regulation or exceeds the permitted use, you will need to obtain permission directly from the copyright holder. To view a copy of this licence, visit http://creativecommons.org/licenses/by/4.0/.

\section{References}

1. Mulliken JB, Burrows PE, Fishman S.J. (2013) Mulliken and Young's vascular anomalies: hemangiomas and malformations.562-594

2. Defnet AM, Bagrodia N, Hernandez SL, Gwilliam N, Kandel JJ (2016) Pediatric lymphatic malformations: evolving understanding and therapeutic options. Pediatr Surg Int 32(5):425-433. https://doi. org/10.1007/s00383-016-3867-4

3. Manning SC, Perkins J (2013) Lymphatic malformations. Curr Opin Otolaryngol Head Neck Surg 21(6):571-575. https://doi. org/10.1097/MOO.0000000000000007

4. Acevedo JL, Shah RK, Brietzke SE (2008) Nonsurgical therapies for lymphangiomas: a systematic review. Otolaryngol Head Neck Surg 138(4):418-424. https://doi.org/10.1016/j.otohns.2007.11.018

5. Shergill A, John P, Amaral JG (2012) Doxycycline sclerotherapy in children with lymphatic malformations: outcomes, complications and clinical efficacy. Pediatr Radiol 42(9):1080-1088. https://doi. org/10.1007/s00247-012-2406-2

6. Ardicli B, Karnak I, Ciftci AO, Tanyel FC, Senocak ME (2016) Sclerotherapy with bleomycin versus surgical excision for extracervical cystic lymphatic malformations in children. Surg Today 46(1):97-101. https://doi.org/10.1007/s00595-015-1128-0

7. Farnoosh S, Don D, Koempel J, Panossian A, Anselmo D, Stanley P (2015) Efficacy of doxycycline and sodium tetradecyl sulfate sclerotherapy in pediatric head and neck lymphatic malformations. Int J Pediatr Otorhinolaryngol 79(6):883-887. https://doi.org/10. 1016/j.ijporl.2015.03.024

8. Eliasson JJ, Weiss I, Hogevold HE, Oliver N, Andersen R, Try K, Tonseth KA (2017) An 8-year population description from a national treatment centre on lymphatic malformations. J Plast Surg Hand Surg 51(4):280-285. https://doi.org/10.1080/2000656X.2016.1254092

9. Cahill AM, Nijs E, Ballah D, Rabinowitz D, Thompson L, Rintoul N, Hedrick H, Jacobs I, Low D (2011) Percutaneous sclerotherapy in neonatal and infant head and neck lymphatic malformations: a single center experience. J Pediatr Surg 46(11):2083-2095. https:// doi.org/10.1016/j.jpedsurg.2011.07.004

10. Tu JH, Do HM, Patel V, Yeom KW, Teng JMC (2017) Sclerotherapy for lymphatic malformations of the head and neck in the pediatric population. J Neurointerv Surg 9(10):1023-1026. https://doi.org/10.1136/neurintsurg-2016-012660

11. Motz KM, Nickley KB, Bedwell JR, Yadav B, Guzzetta PC, Oh AK, Bauman NM (2014) OK432 versus doxycycline for treatment of macrocystic lymphatic malformations. Ann Otol Rhinol Laryngol 123(2):81-88. https://doi.org/10.1177/0003489414523561

12. Kim KH, Sung MW, Roh JL, Han MH (2004) Sclerotherapy for congenital lesions in the head and neck. Otolaryngol Head Neck Surg 131(3):307-316. https://doi.org/10.1016/j.otohns.2004.02.018

13. Okazaki T, Iwatani S, Yanai T, Kobayashi H, Kato Y, Marusasa T, Lane GJ, Yamataka A (2007) Treatment of lymphangioma in children: our experience of 128 cases. J Pediatr Surg 42(2):386-389. https://doi.org/10.1016/j.jpedsurg.2006.10.012

14. Thomas DM, Wieck MM, Grant CN, Dossa A, Nowicki D, Stanley P, Zeinati C, Howell LK, Anselmo DM (2016) Doxycycline sclerotherapy is auperior in the treatment of pediatric lymphatic malformations. J Vasc Interv Radiol 27(12):1846-1856. https:// doi.org/10.1016/j.jvir.2016.08.012

15. Lerat J, Mounayer C, Scomparin A, Orsel S, Bessede JP, Aubry K (2016) Head and neck lymphatic malformation and treatment: clinical study of 23 cases. Eur Ann Otorhinolaryngol Head Neck Dis 133(6):393-396. https://doi.org/10.1016/j.anorl.2016.07.004

16. Chen WL, Huang ZQ, Chai Q, Zhang DM, Wang YY, Wang HJ, Wang L, Fan S (2011) Percutaneous sclerotherapy of massive macrocystic lymphatic malformations of the face and neck using fibrin glue with OK-432 and bleomycin. Int J Oral Maxillofac Surg 40(6):572-576. https://doi.org/10.1016/j.ijom.2011.01.009 
17. Sanlialp I, Karnak I, Tanyel FC, Senocak ME, Buyukpamukcu N (2003) Sclerotherapy for lymphangioma in children. Int J Pediatr Otorhinolaryngol 67(7):795-800

18. Horbach SE, Lokhorst MM, Saeed P, de Gouyon Matignon de Pontouraude CM, Rothova A, van der Horst CM (2016) Sclerotherapy for low-flow vascular malformations of the head and neck: a systematic review of sclerosing agents. J Plast Reconstr Aesthet Surg 69(3):295-304. https://doi.org/10.1016/j.bjps.2015.10.045

19. Chaudry G, Guevara CJ, Rialon KL, Kerr C, Mulliken JB, Greene AK, Fishman SJ, Boyer D, Alomari AI (2014) Safety and efficacy of bleomycin sclerotherapy for microcystic lymphatic malformation. Cardiovasc Intervent Radiol 37(6):1476-1481. https://doi. org/10.1007/s00270-014-0932-z

20. Sacks D, McClenny TE, Cardella JF, Lewis CA (2003) Society of Interventional Radiology clinical practice guidelines. J Vasc Interv Radiol 14(9 Pt 2):S199-S202

21. Yamaki T, Sasaki Y, Hasegawa Y, Osada A, Konoeda H, Hamahata A, Nozaki M, Sakurai H (2017) Percutaneous ultrasound-guided sclerotherapy with polidocanol microfoam for lymphatic malformations. J Vasc Surg Venous Lymphat Disord 5(5):707-714. https://doi.org/10.1016/j.jvsv.2017.03.017

22. Nehra D, Jacobson L, Barnes P, Mallory B, Albanese CT, Sylvester KG (2008) Doxycycline sclerotherapy as primary treatment of head and neck lymphatic malformations in children. J Pediatr Surg 43(3): 451-460. https://doi.org/10.1016/j.jpedsurg.2007.10.009

23. Peters DA, Courtemanche DJ, Heran MK, Ludemann JP, Prendiville JS (2006) Treatment of cystic lymphatic vascular malformations with OK-432 sclerotherapy. Plast Reconstr Surg 118(6):1441-1446. https:// doi.org/10.1097/01.prs.0000239503.10964.11

24. Yang Y, Sun M, Ma Q, Cheng X, Ao J, Tian L, Wang L, Lei D (2011) Bleomycin A5 sclerotherapy for cervicofacial lymphatic malformations. J Vasc Surg 53(1):150-155. https://doi.org/10. 1016/j.jvs.2010.07.019

25. Burrows PE (2013) Endovascular treatment of slow-flow vascular malformations. Tech Vasc Interv Radiol 16(1):12-21. https://doi. org/10.1053/j.tvir.2013.01.003

26. Horbach SER, van de Ven JS, Nieuwkerk PT, Spuls PI, van der Horst C, Reekers JA (2018) Patient-reported outcomes of bleomycin sclerotherapy for low-flow vascular malformations and predictors of improvement. Cardiovasc Intervent Radiol 41(10): 1494-1504. https://doi.org/10.1007/s00270-018-1999-8

27. Hammer J, Seront E, Duez S, Dupont S, Van Damme A, Schmitz S, Hoyoux C, Chopinet C, Clapuyt P, Hammer F, Vikkula M, Boon LM (2018) Sirolimus is efficacious in treatment for extensive and or complex slow-flow vascular malformations: a monocentric prospective phase II study. Orphanet J Rare Dis 13(1):191. https://doi. org/10.1186/s13023-018-0934-Z

28. Strychowsky JE, Rahbar R, O'Hare MJ, Irace AL, Padua H, Trenor CC 3rd (2018) Sirolimus as treatment for 19 patients with refractory cervicofacial lymphatic malformation. Laryngoscope 128(1):269276. https://doi.org/10.1002/lary.26780

29. Yilmaz H, Yilmaz O, Camlidag I, Belet U, Akan H (2017) Single center experience with intralesional bleomycin sclerotherapy for lymphatic malformations. Jpn J Radiol 35(10):590-596. https:// doi.org/10.1007/s11604-017-0672-5

30. Mathur NN, Rana I, Bothra R, Dhawan R, Kathuria G, Pradhan T (2005) Bleomycin sclerotherapy in congenital lymphatic and vascular malformations of head and neck. Int J Pediatr Otorhinolaryngol 69(1): 75-80. https://doi.org/10.1016/j.ijporl.2004.08.008

31. Sainsbury DC, Kessell G, Fall AJ, Hampton FJ, Guhan A, Muir T (2011) Intralesional bleomycin injection treatment for vascular birthmarks: a 5-year experience at a single United Kingdom unit. Plast Reconstr Surg 127(5):2031-2044. https://doi.org/10.1097/ PRS.0b013e31820e923c
32. Lee HJ, Kim TW, Kim JM, Kim GW, Ko HC, Kim BS, Kim MB, Kim HS (2017) Percutaneous sclerotherapy using bleomycin for the treatment of vascular malformations. Int J Dermatol 56(11):11861191. https://doi.org/10.1111/ijd.13733

33. Baskin D, Tander B, Bankaoglu M (2005) Local bleomycin injection in the treatment of lymphangioma. Eur J Pediatr Surg 15(6): 383-386. https://doi.org/10.1055/s-2005-872922

34. Mohan AT, Adams S, Adams K, Hudson DA (2015) Intralesional bleomycin injection in management of low flow vascular malformations in children. J Plast Surg Hand Surg 49(2):116120. https://doi.org/10.3109/2000656X.2014.951051

35. Horbach SE, Rigter IM, Smitt JH, Reekers JA, Spuls PI, van der Horst CM (2016) Intralesional bleomycin injections for vascular malformations: a systematic review and meta-analysis. Plast Reconstr Surg 137(1):244-256. https://doi.org/10.1097/PRS. 0000000000001924

36. Acord M, Srinivasan AS, Cahill AM (2016) Percutaneous treatment of lymphatic malformations. Tech Vasc Interv Radiol 19(4):305311. https://doi.org/10.1053/j.tvir.2016.10.001

37. Gallego Herrero C, Navarro Cutillas V (2017) Percutaneous sclerotherapy of pediatric lymphatic malformations: experience and outcomes according to the agent used. Radiologia 59(5):401-413. https://doi.org/10.1016/j.rx.2017.04.010

38. Burrows PE, Mitri RK, Alomari A, Padua HM, Lord DJ, Sylvia MB, Fishman SJ, Mulliken JB (2008) Percutaneous sclerotherapy of lymphatic malformations with doxycycline. Lymphat Res Biol 6(3-4):209-216. https://doi.org/10.1089/lrb.2008.1004

39. Jamal N, Ahmed S, Miller T, Bent J, Brook A, Parikh S, Ankola A (2012) Doxycycline sclerotherapy for pediatric head and neck macrocystic lymphatic malformations: a case series and review of the literature. Int J Pediatr Otorhinolaryngol 76(8):1127-1131. https://doi.org/10.1016/j.ijporl.2012.04.015

40. Cordes BM, Seidel FG, Sulek M, Giannoni CM, Friedman EM (2007) Doxycycline sclerotherapy as the primary treatment for head and neck lymphatic malformations. Otolaryngol Head Neck Surg 137(6):962-964. https://doi.org/10.1016/j.otohns.2007.08.013

41. Impellizzeri P, Romeo C, Borruto FA, Granata F, Scalfari G, De Ponte FS, Longo M (2010) Sclerotherapy for cervical cystic lymphatic malformations in children. Our experience with computed tomography-guided $98 \%$ sterile ethanol insertion and a review of the literature. J Pediatr Surg 45(12):2473-2478. https://doi.org/10. 1016/j.jpedsurg.2010.07.023

42. Koo HJ, Lee JH, Kim GY, Choi YJ, Baek JH, Choi SH, Nam SY, Kim SY, Suh DC (2016) Ethanol and/or radiofrequency ablation to treat venolymphatic malformations that manifest as a bulging mass in the head and neck. Clin Radiol 71(10):1070 e1071-1070 e1077. https://doi.org/10.1016/j.crad.2016.03.012

43. Khalilzadeh O, Baerlocher MO, Shyn PB, Connolly BL, Devane AM, Morris CS, Cohen AM, Midia M, Thornton RH, Gross K, Caplin DM, Aeron G, Misra S, Patel NH, Walker TG, Martinez-Salazar G, Silberzweig JE, Nikolic B (2017) Proposal of a new adverse event classification by the Society of Interventional Radiology Standards of Practice Committee. J Vasc Interv Radiol 28(10):1432-1437 e1433. https://doi.org/10.1016/j.jvir.2017.06.019

44. Horbach SER, van der Horst C, Blei F, van der Vleuten CJM, Frieden IJ, Richter GT, Tan ST, Muir T, Penington AJ, Boon LM, Spuls PI, Group OC (2018) Development of an international core outcome set for peripheral vascular malformations: the OVAMA project. Br J Dermatol 178(2):473-481. https://doi.org/ 10.1111/bjd.16029

Publisher's note Springer Nature remains neutral with regard to jurisdictional claims in published maps and institutional affiliations. 